\title{
FARMERS' PERCEPTIONS OF CLIMATE CHANGE, ITS ASSOCIATED RISKS AND ADAPTATION METHODS: A CASE STUDY OF GHAZIABAD, UTTAR PRADESH, INDIA
}

\author{
Srishty Kasana $^{1 \rrbracket}$, Dr. Yamini Gupt ${ }^{2} \bowtie$ (D) \\ ${ }^{1}$ PhD Research Scholar, Department of Finance and Business Economics, University of Delhi, New Delhi, India. \\ ${ }^{2}$ Professor, Department of Finance and Business Economics, University of Delhi, New Delhi, India.
}

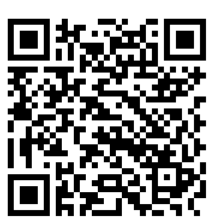

ABSTRACT
This study makes an attempt to explore farmers' perception of climate change, awareness
of adaptation and techniques adopted by them. Study area is Ghaziabad, Uttar Pradesh
because this district is located in seismic zone IV and due to this, district is exposed to
natural and man-made calamities such as, floods, drought, windstorms. Non-parametric
test named Mann-Kendall has been employed to observe monthly trend in the climatic
variables. Minimum temperature and maximum temperature showed an upward trend
in most of the months; however, rainfall shows an insignificant downward trend in most
of the months. The primary survey results indicate that farmers are observing increase
in temperature, erratic rainfall and other changes in climate, but they are not aware of
"climate change" per se. Most farmers believe that "Ancestral Spirits" are the main cause
of the variations taking place in climate. The farmers are aware of the climate shocks and
climate variability. Although farmers haven't taken any concrete steps to combat the
perceived climate changes, they are changing their farming practices.

Received 18 November 2021

Accepted 7 December 2021

Published 31 December 2021

CorrespondingAuthor

Srishty Kasana,

srishtykasana@gmail.com

DOI

10.29121/granthaalayah.v9.i12.2021 .4410

Funding: This research received no specific grant from any funding agency in the public, commercial, or not-for-profit sectors.

Copyright: (C) 2021 The Author(s). This is an open access article distributed under the terms of the Creative Commons Attribution License, which permits unrestricted use, distribution, and reproduction in any medium, provided the original author and source are credited.
Keywords: Trend, Climate Change, Mann-Kendall, Perception, Adaptation.

\section{INTRODUCTION}

Climate change represents the significant variations in the statistical distribution of weather parameters over a long period ${ }^{1}$.

According to Indian Meteorological Department Jha and Tripathi (2017), there exists four seasons in India: winter (January and February), premonsoon (March, April and May), monsoon (June, July, August and September) and postmonsoon (October to December).

The entire year gets divided into four seasons: (i.) Winter (January and February); (ii.) Pre-monsoon or Hot climate season (March-May); (iii.) Southwest or summer, monsoon season (June-September); (iv.) Post monsoon season (October-December). Year-wise fluctuations in the weather and happening of climatic shocks/extremes in respect of these four seasons are: 
1) Cold wave, Fog, Snow storms and Avalanches

2) Hailstorm, Thunderstorm and Dust storms

3) Heat wave

4) Tropical cyclones and Tidal waves

5) Floods, Heavy rain and Landslides, and

6) Droughts

As mentioned by ICRISAT (2012), climate change has emerged as a threat to livelihood sustainability of the current times, imposing impending danger to our food security and threat on agricultural productivity. Currently, scientists are able to recognise and decontaminate the forecasts of future location specific climate circumstances that farmers have to deal with. According to INCCA ICRISAT (2012), by the year 2030, an expected increase in the annual average surface air temperature by $1.7^{\circ} \mathrm{C}$ to $2.0^{\circ} \mathrm{C}$ will be experienced by India. According to the forecasts of the same study, by 2030, most areas of the Indian subcontinent are going to experience a fall in rainy days.

If we talk about the forthcoming 50-100 years, forecasts made about climate change are quite distressing. Apart from the problem of high level of poverty, semiarid tropics (SAT) of India are encountering some really serious issues such as, truncated and indeterminate rainfall, poor soil fertility, improper infrastructure, pressure created due to high inhabitants. The forthcoming government of India must combat the variations displayed in climate and the fall in yield which is caused by those variations, however, at the same time government has to feed the growing population by increasing the productivity (ibid).

According to UNFCC Tripathi and Mishra (2017), adaptation to climate change (CC) refers to curtailing the undesirable/negative effects of climate change and enhancing the positive impacts of CC; in order to enhance the positive effects, modifications are required in the system. There are different levels of government where adaptation can be opted i.e., regional, national, sub-national and local. Players who are placed at the local level of adaptation, they are the ones most able to experience the severity caused by climate change.

In order to achieve adaptation, two steps are required i.e., first, we need to observe climate change and the risks associated with it; then in the next stage, proper steps should be implemented so that negative effects of climate change can be curtailed. How accurately these perceptions are formed, it is directly connected with knowledge and access to information. Further, knowledge is highly dependent upon accomplishments in the field of education and experience of the person. In the process of perception, understanding of reasoning and sensory information is required Tripathi and Mishra (2017).

By employing focus group research method (FGR), data was obtained from scheduled caste (SC) and other backward class (OBC) farmers in two villages of Ghaziabad (Uttar Pradesh) to detect farmers' perceptions of climate change and its associated risks, and adaptation techniques. We focus on SC and OBC farmers because to socially and economically backward and climate change may act as an additional threat to their current as well as future survival. Scheduled Tribe (ST) farmers could not be included in the study (as per the census 2011, there aren't any ST farmer(s) in the surveyed villages ${ }^{2}$ ). According to the figures released by

${ }^{2}$ Census 2011 http://censusindia.gov.in/2011census/dchb/0909_PART_B_DCHB_GHAZIABAD.pdf 
Directorate of Economics \& Statistics (as cited in Agricultural Statistics 2016 ${ }^{3}$ ), Uttar Pradesh contributed highest percentage of wheat in India's total wheat production i.e., $28.74 \%$. Any kind of variation in climate or happening of extreme climate events would affect the wheat production of the state which in turn would be a threat to India's food production. Ghaziabad was selected because it is a drought prone area. According to Disaster Management (Govt. of Uttar Pradesh ${ }^{4}$ ), Ghaziabad is under seismic zone IV and it is highly vulnerable to natural and man-made calamities like floods, drought etc. According to census 2011, there were 8 blocks in Ghaziabad- Bhojpur, Dhaulana, Garhmukteshwar, Hapur, Loni, Muradnagar, Razapur and Simbhawali. Currently there are four blocks in Ghaziabad namelyRajapur, Bhojpur, Muradnagar and Loni ${ }^{5}$. With the help of simple random sampling, district Loni was selected. Further, village Dharipur and Bhoopkhedi were selected in Loni with the help of simple random sampling.

The outcomes of this study will bring up the major problems faced by farmers due to climate change and to understand whether they are able to cope up with it or not. Keeping 'Inclusiveness' in mind, agriculture sector cannot grow and sustain by ignoring these small and poor famers. These farmers should be the focus so that the chances of instability in their income generated due to the climate change can be dealt with properly and climate resilience policies can be formed.

Given this background, the following research questions have been put forward by the current study:

- Which type (upward/downward) of trend is existing in the climate variables of Ghaziabad?

- What are the farmers' perceptions of climate change and the associated risks?

- Does the trend observed in climate variables fall in line with farmers' perception (and information) of climate change?

- What are the different adaptation techniques adopted by farmers?

- What is the estimated loss suffered by farmers (land holding size-wise and social class wise)?

The remainder of this paper is organised as follows: Section 2 talks about the major objectives of the study. Section 3 describes the research methodology and study area. Section 4 reveals the major findings of this study and section 5 provides the concluding remarks of this study.

\section{OBJECTIVES}

The study objectives encompass the following aspects of the study theme:

1) To identify a pattern in the monthly data of Minimum Temperature, Maximum Temperature and Rainfall in past 118 years (1901-2018).

2) To identify the farmers' perceptions of climate change, its associated risks and their knowledge of adaptation methods.

3) To estimate the loss experienced by farmers (land holding size-wise and social class wise) of Ghaziabad due to drought(s) that took place in past five years.

4) To identify the adaptation measures used by farmers.

${ }^{3}$ Agricultural Statistics 2016; Retrieved from: https://eands.dacnet.nic.in/PDF/Glance-2016.pdf

4 Disaster Management, Ghaziabad: https://ghaziabad.nic.in/en/disaster-management/

5 https://ghaziabad.nic.in/en/subdivision-blocks/ 


\section{STUDY AREA AND METHODOLOGY 3.1. AGRICULTURAL PROFILE OF UTTAR PRADESH (U.P)}

Uttar Pradesh (UP) is located in the northern part of India and surrounded by Rajasthan to West, Haryana and Delhi to northwest, Uttarakhand to north, Bihar to east, Jharkhand to south east and Madhya Pradesh to south west. UP covers approx 93,933 (243290 KM Square) area and is the fifth largest state of India. According to the census of 2011, population of UP was 200 million, which consisted $16.49 \%$ of India's total population. There are mainly nine agroclimatic zones in this state i.e., Tarai Region, Western Plain Region, Central Western Region, South Western Region, Central Plain Region, Bundelkhand Region, North Eastern Region, eastern Region and Vindhayachal Region Roy and Ahmad (2015). In this state, people rely on agriculture for their survival. 70 percent of Uttar Pradesh's population is dependent on agriculture and allied sectors. The contribution of agriculture to State Domestic Product (SDP) was $24.11 \%$ at constant (1999-2000) prices for 2009-10. The GSDP from agriculture and allied sector at constant (1999-2000) prices was Rs. 602608 million in 1999-2000 which went upto Rs.748134 million in 2009-10, thereby displaying $24.15 \%$ upsurge over time.

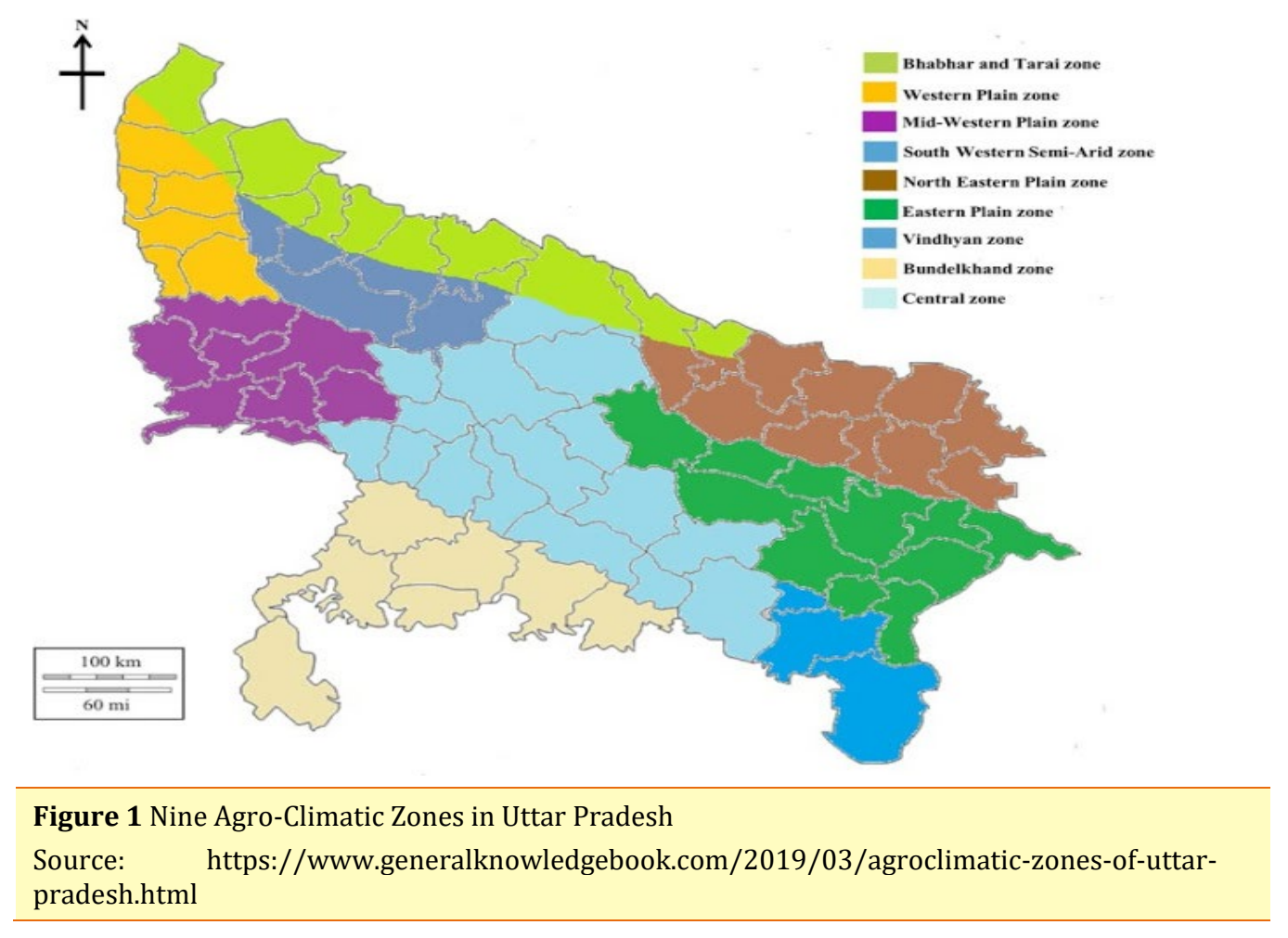

\subsection{SAMPLE DISTRICT}

Ghaziabad is located in the National Capital Region (NCR) and it is known as the industrial district of the state. In terms of population density, this district has 3971 persons per square $\mathrm{km}$, which is considered unusually high. Geographical area is $1179 \mathrm{sq} \mathrm{km}$ and population is 4,681,645. It is among the most urbanized districts of UP, percentage of people residing in urban area is $67.55 \%$. Area under cultivation is $73 \%$ and net sown area is 1.5 lakh hectares, out of which $93 \%$ is irrigated. In this district, the main crop which is grown by farmers is wheat, followed by paddy and 
coarse grains. Sugarcane and potato are othe two important crops grown in this district (Tripathi, n.d).

\subsection{METHODS}

In order to collect the information, the current study employs Focus Group Method (FGM) and a detailed questionnaire. Morgan Tripathi and Mishra (2017) put forward that FGM assist to understand the complexity of people's thinkingunderstanding- perception of the phenomena being studied and discussions among certain entities are organised. With the help of FGM, researcher can save money and time and collect various information on a specific topic.

In this research work, thirty ${ }^{6}$ farmers were selected randomly and were surveyed; in order to obtain the targeted information, two groups were formed i.e., one group consisted of the farmers belonging to the Schedule Caste and other group belonging to Other Backward Classes (OBC). Farmers who belonged to the age group of 40-60 with at least 20 years of farming experience, were considered for this study. 15 farmers formed one group; thus, two two groups were formed respectively. The selection criterion (i.e., at least 20 years of farming experience) helped us to understand long-term variations which are taking place in agricultural practices and climate change in surveyed villages. In order to analyse the quantitative information collected through interviews, SPSS (statistical software) and STATA were used. With the help of bar graphs, pie charts and histograms, the quantitative and qualitative information is presented in this paper. Further, rainfall, minimum temperature and maximum temperature of Ghaziabad was observed from 1901 to 2018.

The questionnaire which is used in this study, helped us to understand the information in an orderly way, such as characteristics of the households related to socio-economic and demographic structures, negative imprints left by flood and drought, coping and adaptation plans, loss and damage allied with helplessness to tackle and adapt proficiently. Focus Group Discussions (FGD) permitted us to enquire about participants' queries that required in-depth responses. The FGD complemented the household study, as they collected qualitative information on how specific floods and droughts can lead to loss and damage among local population.

\section{DATA AND ANALYSIS}

Secondary data of minimum temperature, maximum temperature and rainfall has been accessed from three websites: India Water Portal, World Weather Online and Indian Meteorological Department (IMD), for the studied time period of 19012018. As mentioned in the beginning of this paper, Uttar Pradesh contributes highest percentage of wheat (i.e., 28.74\%) in India's total wheat production and in Ghaziabad, wheat is the main grown crop, thus, the current study only covers the wheat growers and the wheat crop.

\subsection{MANN KENDALL TEST}

In order to observe trend in climatic variables of Ghaziabad, Mann-Kendall ${ }^{7,8}$ method was applied to observe trend in climatic variables. The null hypothesis (H0) is that there is no trend in over time; the alternate hypothesis (H1) is that there is a

\footnotetext{
${ }^{6}$ As mentioned by Hogg, Tanis and Zimmerman in their book 'Probability and Statistical Inference (9 ${ }^{\text {th }}$ edition; page 202): generally, if $\mathrm{n}$ is greater than 25 or 30, approximations will be good. Retrieved from: https://fac.ksu.edu.sa/sites/default/files/677_fr37hij.pdf

${ }^{7}$ Mann, H.B. (1945). Nonparametric tests against trend. Econometrica, vol. 13, pp. 245-259.
} 
trend over time. The exact equations used to calculate Mann-Kendall Statistics $S$, $V(S)$ and standardized test statistics $Z$ are given as:

$$
\begin{aligned}
& S=\sum_{k=1}^{n-1} \sum_{j=k+1}^{n} \operatorname{sgn}\left(x_{j}-x_{k}\right) \\
& \operatorname{sgn}\left(x_{j}-x_{k}\right)=\left\{\begin{array}{l}
+1 \text { if } x_{j}-x_{k}>0 \\
0 \text { if } x_{j}-x_{k}=0 \\
-1 \text { if } x_{j}-x_{k}<0
\end{array}\right\}
\end{aligned}
$$

where $n$ is the number of observed data series, $x_{j}$ and $x_{k}$ are values in periods $j$ and $\mathrm{k}$, respectively, and $\mathrm{j}>\mathrm{k}$. A positive value of $\mathrm{S}$ is an indicator of an increasing trend, while a negative value indicates a decreasing trend. To statistically quantify the significance of the above trend, Kendall presents a normal-approximation test for data sets with more than 10 values, and there are not many tied values within the data set. The normalised test statistics $\mathrm{Z}$ is as under,

$$
Z=\left\{\begin{array}{ll}
\frac{S-1}{\sqrt{\operatorname{VAR}(S)}} & \text { if } S>0 \\
0 & \text { if } S=0 \\
\frac{S+1}{\sqrt{\operatorname{VAR}(S)}} & \text { if } S<0
\end{array}\right\}
$$

$\operatorname{VAR}(\mathrm{S})$ is determined as:

$$
\operatorname{VAR}(S)=\frac{1}{18}\left[n(n-1)(2 n+5)-\int_{p-1}^{q} t_{p}\left(t_{p}-1\right)\left(2 t_{p}+5\right)\right]
$$

where $q$ is the number of tied groups and tp is the number of data values in the p-th group. The Z1- $\alpha / 2$ is the critical value of $Z$ from the standard normal table; for 90 per cent level of confidence the value of $\mathrm{Z} 1-\alpha / 2$ is 1.64 . If $|\mathrm{Z}|>\mathrm{Z} 1-\alpha / 2$, null

\begin{tabular}{|c|c|c|c|c|c|c|}
\hline Month & $\begin{array}{l}\text { Kendall } \\
\text { Tau }\end{array}$ & $\mathbf{S}$ & $\operatorname{Var}(S)$ & $\begin{array}{c}\text { P- } \\
\text { Value }\end{array}$ & Alpha & Interpretation \\
\hline January & 0.093 & 639 & 429.928 & 0.138 & 0.05 & Insignificant Upward Trend \\
\hline February & 0.241 & 1664 & 429.915 & 0 & 0.05 & Significant Upward Trend \\
\hline March & 0.203 & 1402 & 429.929 & 0.001 & 0.05 & Significant Upward Trend \\
\hline April & 0.258 & 1777 & 429.931 & 0.0001 & 0.05 & Significant Upward Trend \\
\hline May & 0.224 & 1542 & 429.922 & 0 & 0.05 & Significant Upward Trend \\
\hline June & 0.066 & 454 & 429.922 & 0.292 & 0.05 & Insignificant Upward Trend \\
\hline July & 0.116 & 802 & 429.932 & 0.062 & 0.05 & Insignificant Upward Trend \\
\hline August & 0.151 & 1042 & 429.922 & 0.015 & 0.05 & Significant Upward Trend \\
\hline September & -0.117 & -807 & 429.931 & 0.061 & 0.05 & $\begin{array}{c}\text { Insignificant Downward } \\
\text { Trend }\end{array}$ \\
\hline October & 0 & 0 & 429.932 & 1 & 0.05 & Insignificant Upward Trend \\
\hline November & 0.1944 & 1341 & 429.924 & 0.0018 & 0.05 & Significant Upward Trend \\
\hline December & 0.2857 & 1969 & 429.897 & 0 & 0.05 & Significant Upward Trend \\
\hline \multicolumn{7}{|c|}{ Source: Author's own calculation } \\
\hline
\end{tabular}
hypothesis is rejected and a significant trend exists in the time series. A positive value of $\mathrm{Z}$ indicates an upward trend while its negative value indicates a downward trend in variable. 


\begin{tabular}{|c|c|c|c|c|c|c|}
\hline Month & $\begin{array}{l}\text { Kendall } \\
\text { Tau }\end{array}$ & $\mathbf{S}$ & $\operatorname{Var}(\mathbf{S})$ & $\begin{array}{c}\text { P- } \\
\text { Value }\end{array}$ & Alpha & Interpretation \\
\hline January & 0.2192 & 1513 & 429.926 & 0.0004 & 0.05 & Significant Upward Trend \\
\hline February & 0.2602 & 1796 & 429.929 & 0 & 0.05 & Significant Upward Trend \\
\hline March & 0.131 & 904 & 429.933 & 0.0357 & 0.05 & Significant Upward Trend \\
\hline April & 0.266 & 1835 & 429.928 & 0 & 0.05 & Significant Upward Trend \\
\hline May & 0.2136 & 1473 & 429.921 & 0.0006 & 0.05 & Significant Upward Trend \\
\hline June & 0.0423 & 292 & 429.933 & 0.4985 & 0.05 & Insignificant Upward Trenc \\
\hline July & 0.1295 & 892 & 429.882 & 0.0382 & 0.05 & Significant Upward Trend \\
\hline August & 0.166 & 1145 & 429.924 & 0.0078 & 0.05 & Significant Upward Trend \\
\hline September & -0.0602 & -415 & 429.921 & 0.3356 & 0.05 & $\begin{array}{c}\text { Insignificant Downward } \\
\text { Trend }\end{array}$ \\
\hline October & 0.1403 & 968 & 429.932 & 0.0245 & 0.05 & Significant Upward Trend \\
\hline November & 0.4058 & 2800 & 429.932 & 0 & 0.05 & Significant Upward Trend \\
\hline December & 0.4596 & 3171 & 429.928 & 0 & 0.05 & Significant Upward Trend \\
\hline
\end{tabular}

\begin{tabular}{|c|c|c|c|c|c|c|}
\hline m & $\begin{array}{l}\text { Kendall } \\
\text { Tau }\end{array}$ & $\mathbf{S}$ & $\operatorname{Var}(\mathrm{S})$ & $\begin{array}{c}\text { P- } \\
\text { Value }\end{array}$ & Alpha & Interpretation \\
\hline January & -0.0896 & -618 & 429.927 & 0.1513 & 0.05 & $\begin{array}{c}\text { Insignificant Downward } \\
\text { Trend }\end{array}$ \\
\hline February & -0.0001 & -1 & 429.829 & 1 & 0.05 & $\begin{array}{c}\text { Insignificant Downward } \\
\text { Trend }\end{array}$ \\
\hline March & 0.1358 & 937 & 429.919 & 0.0295 & 0.05 & Significant Upward Trend \\
\hline April & -0.0926 & -635 & 429.549 & 0.14 & 0.05 & $\begin{array}{c}\text { Insignificant Downward } \\
\text { Trend }\end{array}$ \\
\hline May & 0.0599 & 413 & 429.904 & 0.3379 & 0.05 & Insignificant Upward Trend \\
\hline June & 0.042 & 290 & 429.937 & 0.5015 & 0.05 & Insignificant Upward Trend \\
\hline July & -0.1071 & -739 & 429.938 & 0.0861 & 0.05 & $\begin{array}{c}\text { Insignificant Downward } \\
\text { Trend }\end{array}$ \\
\hline August & -0.0041 & -28 & 429.937 & 0.9499 & 0.05 & $\begin{array}{c}\text { Insignificant Downward } \\
\text { Trend }\end{array}$ \\
\hline September & 0.0013 & 9 & 429.938 & 0.9852 & 0.05 & Insignificant Upward Trend \\
\hline October & -0.0985 & -677 & 429.776 & 0.1157 & 0.05 & $\begin{array}{c}\text { Insignificant Downward } \\
\text { Trend }\end{array}$ \\
\hline November & -0.0548 & -351 & 418.376 & 0.4028 & 0.05 & $\begin{array}{c}\text { Insignificant Downward } \\
\text { Trend }\end{array}$ \\
\hline December & -0.0241 & -162 & 427.254 & 0.7063 & 0.05 & $\begin{array}{c}\text { Insignificant Downward } \\
\text { Trend }\end{array}$ \\
\hline
\end{tabular}

Source: Author's own calculation

According to the results shown, in Table 1, maximum temperature shows an upward trend in the month of February, March, April, May, August, November and December. In Table 2, Minimum temperature shows upward trend in the month of January, February, March, April, May, July, August, October, November and December. However, Rainfall (Table 3) does not show significant upward/downward trend in most of the months except in the month of March (upward trend). This information was used to judge the perceptions which were 
revealed by the farmers regarding climate change during the focus groups and while answering the questionnaire.

\subsection{RESULTS OF PRIMARY SURVEY}

By using the information obtained from farmers surveyed in the primary survey, results have been articulated and presented in the following section (4.2.1 to 4.2.6):

\subsubsection{EXPERIENCE OF DROUGHT}

Farmers reported that the last drought took place in 2017. According to the farmers, if they experience very low rainfall and extreme heat, they usually predict that drought is about to hit the village. Majority of the farmers said that they had experienced drought once every two years. However, 7 farmers reported that they have experienced drought less than once every two years. In the past five years (2015-2020), both the villages (i.e., Dharipur \& Bhoopkhedi) have experienced one major drought in 2017.

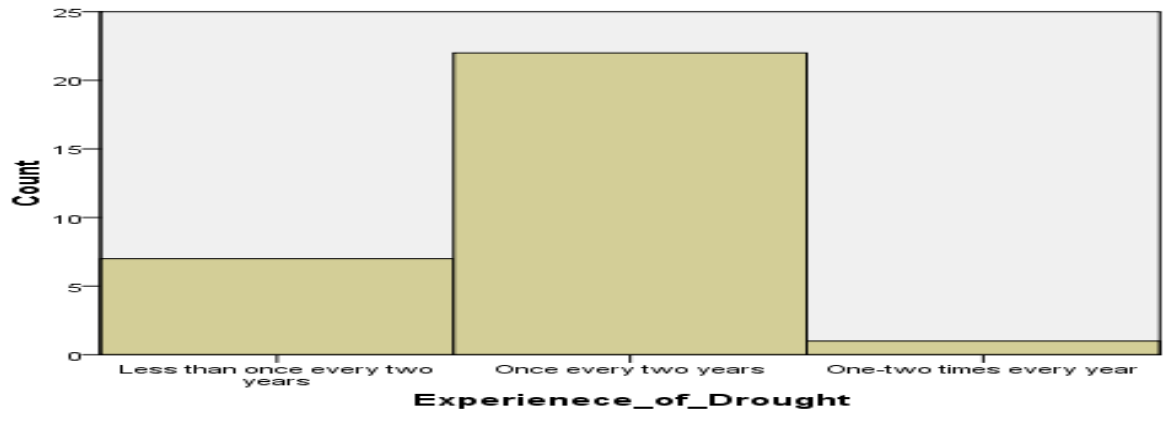

Figure 2 Experience of Drought

Source: Author's calculations based upon primary data

\subsubsection{FARMERS' PERCEPTION OF CLIMATE CHANGE AND ITS IMPACT}

It was noticed that in past 20 years, farmers are able to recognize that the changes have taken place in warming, rainfall or variability in rainfall, variability in weather, but did not know that these changes are taking place due to climate change. This finding executes that surveyed farmers have low level of education as well as awareness. Agricultural extension services need to be made strong in these villages. Extension services play an important role in the perception of and adaptation to climate change. Bryan et al. Tripathi and Mishra (2017) put forward that households that are unable to obtain visits from extension agents, had higher possibility of either not perceiving the climate change or perceiving it wrongly.

As revealed by the survey, $67 \%$ farmers observed an upsurge in temperature in the past 20 years while $23 \%$ of the total farmers felt that there is no increase or decrease in the temperature.

$63 \%$ farmers reported that there had been a decline in rainfall in past 20 years and $24 \%$ farmers felt that rainfall had remained same in the given time span of 20 years.

$73 \%$ farmers observed that rainfall had become more erratic, $20 \%$ said that rains come earlier followed by $7 \%$ farmers who observed rains come later. 
Most farmers displayed their lack of awareness regarding the causes of climate change. "Ancestral spirits" were identified as the chief cause of climate change followed by "God", "Pollution" and "change in the direction of wind". Low level of education is possibly the prime reason behind these answers provided by these farmers. During the Focus Group Discussion (FGD), farmers also said that due to rising crime levels in India, God has become unhappy and this is leading to the increased frequency of floods and droughts. More than $60 \%$ of the farmers surveyed, agreed on the fact that the number of malaria/dengue/chikungunya/TB/typhoid/cholera/Jaundice etc cases have increased over the last 20 years. $73 \%$ farmers reported that the incident of livestock disease has increased in the past 20 years and 17\% farmers said that the incidents have "stayed the same".

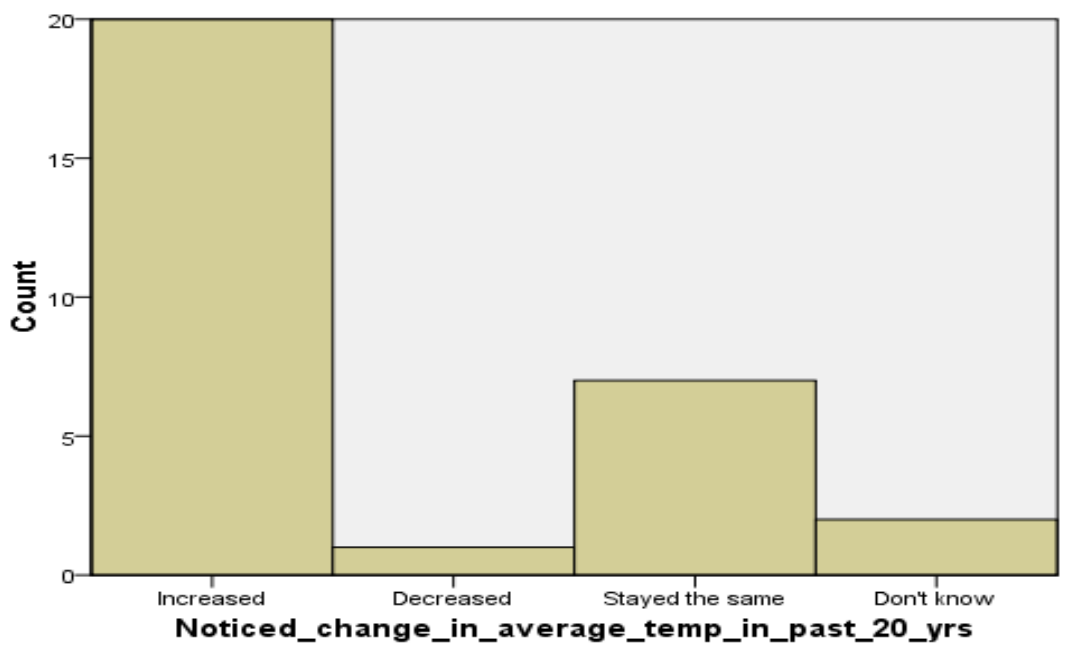

Figure 3 Noticed changes in average temperature in past 20 years

Source: Author's calculations based upon primary data

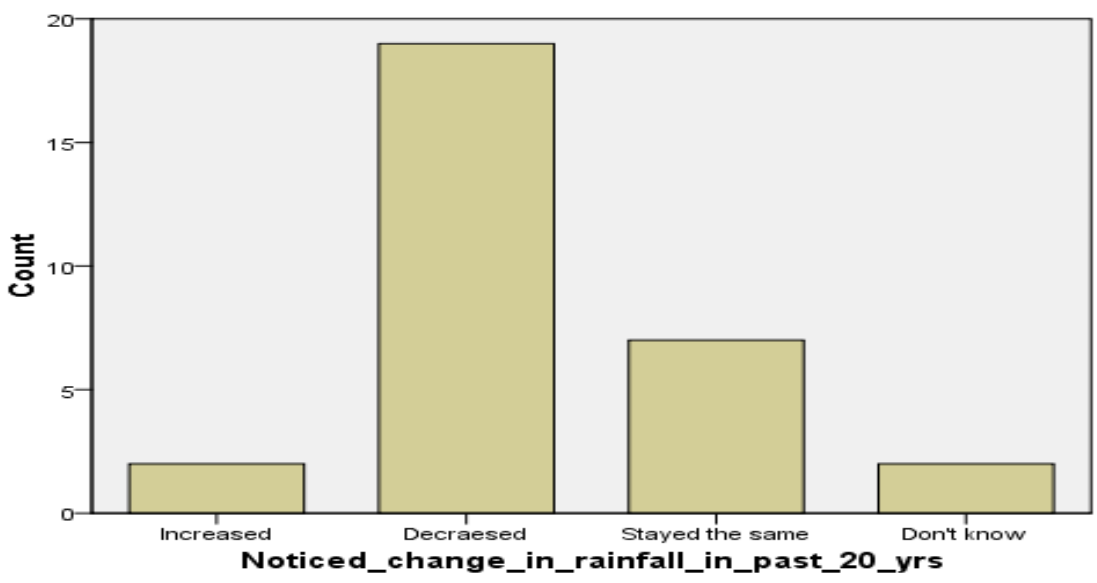

Figure 4 Noticed changes in rainfall in past 20 years

Source: Author's calculations based upon primary data 


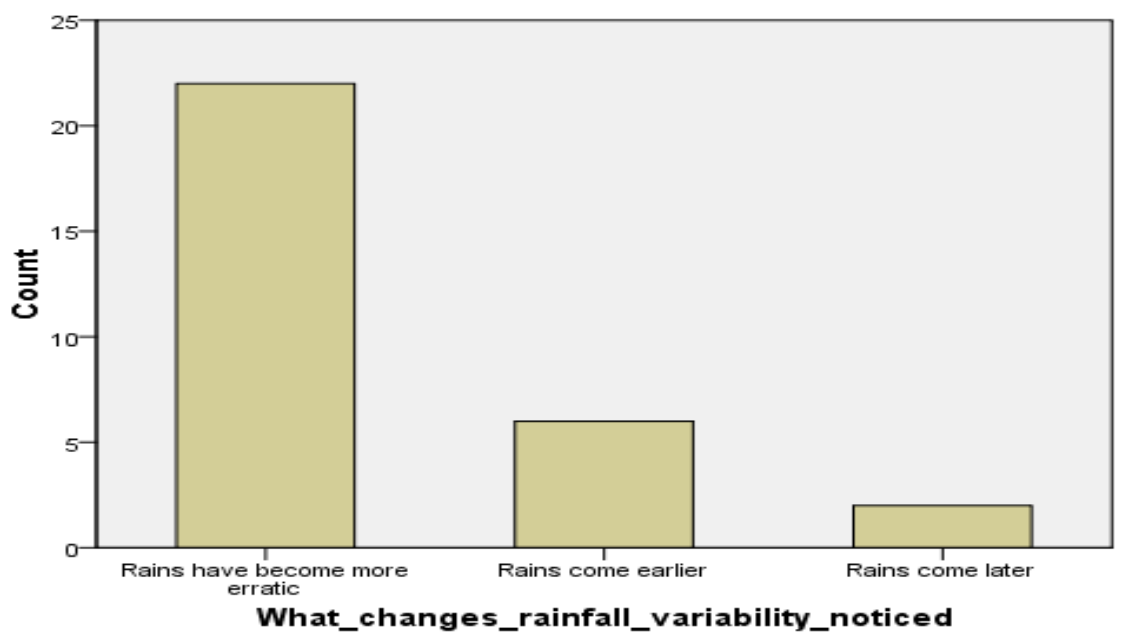

Figure 5 Type of changes observed in rainfall variability

Source: Author's calculations based upon primary data.

\subsubsection{MEASURING THE IMPACT OF DROUGHT}

All farmers surveyed, had suffered loss from the drought (2017) in different ways. $67 \%$ farmers reported that the severity of the drought was very high and $23 \%$ farmers mentioned that severity was medium. Majority of the farmers surveyed felt the adverse effect of drought on crop production. However, rest of the farmers experienced the adverse impact on food prices and livestock.

$57 \%$ farmers didn't opt for any coping strategy and rest of the farmers responded "Don't Know" when asked about the coping strategy adopted. Although these farmers were neither aware of the coping strategies nor tried to adopt any strategies, when asked about the non-farming coping strategies: "borrowed from relatives/friends" turned out to be the favourite non-farming coping strategy as around $63 \%$ farmers opted for this option, 30\% farmers looked for extra income, one farmer preferred selling his property while other one farmer did out migration to other city.

Change in crop pattern and selling livestock was the preferred farm based coping strategy followed by keeping land fallow and "sold part of land for alternative".

Changing the crop calendar was opted by $80 \%$ farmers as an adaptation technique, $17 \%$ farmers relied on "using less water consuming crops" as adaptation technique followed by keeping land unsown after the possibility of drought, changed crop rotation and reduced livestock animals were adaptation techniques adopted by rest of the farmers. However, these farmers were not aware of the term "adaptation techniques."

Around 96\% farmers surveyed had access to the mass media for information regarding agriculture as compared to $4 \%$ farmers who didn't have access to any mass media. Radio and Television came out to be the most used forms of mass media followed by mobile phone to get information on agriculture.

As revealed by Table 4, impact of drought was felt "high" on employment, spending on festivals, schooling of children, caused population migration, affecting animal health and depletion in ground water. However, "very high" impact was experienced in terms of hopelessness and sense of loss, animal health, reduction in 
household income and damage to crops. "Medium" impact was felt on threat to household food security, causing malnutrition, and effects on human health. Nevertheless, "less" and "very less" impact was felt on conflicts over resources in society, loss of livestock and change in soil salinity.

\begin{tabular}{|c|c|c|c|c|c|}
\hline & $\begin{array}{l}\text { Very } \\
\text { High }\end{array}$ & High & Medium & Less & $\begin{array}{l}\text { Very } \\
\text { Less }\end{array}$ \\
\hline Loss of employment & $20 \%$ & $50 \%$ & $26.67 \%$ & $3.33 \%$ & --- \\
\hline Reduction in spending on festivals & $16.66 \%$ & $46.67 \%$ & $6.67 \%$ & $23.33 \%$ & $6.67 \%$ \\
\hline Threat to household food security & $10 \%$ & $26.67 \%$ & $40 \%$ & $20 \%$ & $3.33 \%$ \\
\hline Caused limited food preferences & $3.33 \%$ & $10 \%$ & $43.33 \%$ & $30 \%$ & $16.67 \%$ \\
\hline $\begin{array}{c}\text { Caused conflicts over resources in } \\
\text { society }\end{array}$ & --- & --- & $26.67 \%$ & $36.66 \%$ & $36.60 \%$ \\
\hline Affected schooling of children & $30 \%$ & $50 \%$ & $10 \%$ & --- & --- \\
\hline Caused population migration & $13.33 \%$ & $26.67 \%$ & $23.33 \%$ & $16.67 \%$ & $10 \%$ \\
\hline Caused malnutrition & --- & $10 \%$ & $40 \%$ & $36.67 \%$ & $6.67 \%$ \\
\hline Caused hopelessness and sense of loss & $43.33 \%$ & $36.67 \%$ & $16.67 \%$ & --- & --- \\
\hline Affected human health & $10 \%$ & $33.33 \%$ & $36.67 \%$ & $13.33 \%$ & $3.33 \%$ \\
\hline Affected animal health & $40 \%$ & $40 \%$ & $13.33 \%$ & $6.67 \%$ & --- \\
\hline Caused loss of livestock & $10 \%$ & $26.67 \%$ & $23.33 \%$ & $33.33 \%$ & $3.33 \%$ \\
\hline $\begin{array}{l}\text { Caused reduction in household } \\
\text { income }\end{array}$ & $43.33 \%$ & $40 \%$ & $16.67 \%$ & --- & --- \\
\hline Damage caused to crops by pests & $46.67 \%$ & $40 \%$ & $13.33 \%$ & --- & --- \\
\hline Depletion in ground water & $23.33 \%$ & $53.33 \%$ & $16.67 \%$ & --- & --- \\
\hline Change in soil salinity & $3.33 \%$ & $16.66 \%$ & $36.67 \%$ & $43.33 \%$ & $3.33 \%$ \\
\hline
\end{tabular}

\subsubsection{ESTIMATED LOSS OF FARMERS (LAND HOLDING WISE AND SOCIAL CLASS WISE)}

We defined different categories of land holdings in terms local measurements used by the farmers of this village. Famers who had land below 3.87 Bigha $^{8}$ were declared as Marginal farmers; 3.87-7.74 Bigha holders as small farmers; 7.74-15.48 Bigha as Semi Medium; 15.48-38.7 Bigha as Medium; 38.7s and more as large farmers.

Total number of farmers were $30,50 \%$ were SC farmers and $50 \%$ OBC farmers. Out of 15 SC farmers, 9 were marginal and 6 were small. We couldn't find any SC farmer who had land size holding more than 7.74 Bigha. More than $50 \%$ of the SC marginal farmers reported their loss due to drought was Rs.10,000 to 20,000 followed by $20,000-30,000$ and $0-10,000$. However, $50 \%$ of the SC small farmers reported their loss to be 10,000-20,000 followed by 20,000-30,000 and few farmers reported their loss to be $0-10,000$.

We couldn't find any OBC marginal farmer in the two villages studied in this research work. OBC farmers are comparatively well off than SC farmers. Out of 15 OBC farmers, 5 were small; 4 were semi-medium and 6 were medium. All OBC semimedium farmers estimated their loss to be 20,000-30,000. Nevertheless, 50\% OBC medium farmers experienced the loss of $30,000-40,000$. More than $50 \%$ OBC small farmers faced the loss of 20,000-30,000 followed by 10,000-20,000.

${ }^{8}$ One bigha $=0.25$ hectare; retrieved from: Department of Land Resources, Govt of India https://dolr.gov.in/sites/default/files/lrc_codes_list_finaldraft300908reviseda.pdf 


\subsubsection{PERCEPTION OF CHANGES IN THE ONSET AND OFFSET OF SEASONS}

More than $60 \%$ of the farmers reported that onset/offset of cold season has been delayed in the last 20 years. Out of 30 farmers, 25 experienced an early onset/offset of hot season. Approx. 50\% farmers experienced a delay in onset/offset of rainy season.

\subsubsection{CROP SPECIFIC STRATEGIES USED BY FARMERS IN ORDER TO MITIGATE THE EFFECTS OF CLIMATE CHANGE}

Sowing late is the preferred crop specific strategy used by farmers to minimize the negative effects of climate change. Farmers were unaware about crop specific strategies to mitigate the effects of climate change, however, when this question was asked to them and options were provided in the questionnaire, they could identify "sowing late" as the preferred strategy.

\section{CONCLUSION}

The study identifies trends in climate variables using monthly data over the time period of 1901-2018 for district Ghaziabad of Uttar Pradesh, India. Minimum temperature and maximum temperature show a significant upward trend in most of the months; however, rainfall shows insignificant downward trend in most of the months. The Mann-Kendall (MK) test gives an interesting insight about the temperature and rainfall data of Ghaziabad. Before understanding farmers' perception of climate change, it is very important to see whether the secondary data available on climate variables supports the perception (information) provided by these farmers. The approximations in many cases tend to be weak on account of the poor quality of data ${ }^{2}$.

Adaptation process involves two steps-first, recognising climate change and its allied risks; second, providing response to perceived deviations to minimize their adverse bearings. Being a cognitive process, perception comprises obtaining sensory information and then interpreting it. The precision of perception is an indispensable condition for a significant response, which in turn is dependent upon knowledge and experience.

Against this backdrop, the current study tries to make an effort to recognize farmers' perception of climate change and its related risks. It also attempts to detect the vicissitudes in technology and production practices opted by farmers to alleviate losses from climate change. There are certain limitations ${ }^{3}$ of the survey conducted for the current study. Majority of the farmers experienced drought once every two years. More than $50 \%$ of the farmers surveyed reported that they have observed an upsurge in temperature but decline in rainfall in past 20 years and rainfall has become more erratic; the same was indicated by the MK statistic. It was also observed that farmers were not at all aware about the causes of climate change. "Ancestral spirits" were identified as the chief cause behind climate change followed by "God", "Pollution" and "change in the direction of wind". Low level of education is the prime cause of such answers provided by these farmers. More than $60 \%$ of the

farmers surveyed, agreed on the fact that the number of malaria/dengue/chikungunya/TB/typhoid/cholera/Jaundice etc. cases have increased over the last 20 years. Out of 30, 22 farmers reported that the incident of livestock disease have increased in past 20 years. 
Although these farmers were neither aware of the coping strategies nor tried to adopt any strategies, when they were asked about the non-farming coping strategies: "borrowed from relatives/friends" turned out to be the favourite nonfarming coping strategy as around 19 farmers have practised this option. Change in crop pattern and selling livestock came out to be the preferred farm based coping strategy followed by keeping land fallow and selling part of land for alternative. 'Changes in crop calendar' was opted by 24 farmers as an adaptation technique, and all farmers didn't know that it's an adaptation technique. Sowing late is the preferred crop specific strategy used by farmers to mitigate the effects of climate change, followed by using more fertilizers and using more seed. Around $65 \%$ of the farmers reported that the severity of the drought was "High" and adverse effect of drought was felt on crop production.

More than $50 \%$ SC marginal farmers reported to have incurred a loss of around Rs. 10000-20000 followed by 20,000-30,000 and 0-10,000. However, 50\% SC small farmers reported their loss to be around 10,000-20,000 followed by 20,000-30,000 and few farmers reported their loss to be $0-10,000$. All OBC semi-medium farmers estimated their loss to be 20,000-30,000. Nevertheless, around 50\% OBC medium farmers experienced a loss of 30,000-40,000. More than 50\% OBC small farmers faced the loss of 20,000-30,000 followed by 10,000-20,000. While talking to these $\mathrm{SC}$ and $\mathrm{OBC}$ farmers, it was observed that $\mathrm{OBC}$ farmers are in a better position as compared to SC farmers in terms of financial status.

\section{REFERENCES}

Chen, H., Guo, S., Xu, C. Y. and Singh, V. P., (2007), "Historical temporal trends of hydro-climatic variables and runoff response to climate variability and their relevance in water resource management in the Hanjiang basin", Journal of Hydrology, 344, 171-184. Retrieved from https://doi.org/10.1016/j.jhydrol.2007.06.034

De, U.S., Dube, R.K., \& Rao, P. (2015), "Extreme weather events over India in the last 100 years". J. Ind. Geophys. Union, 9(3), pp-173-187.

Disaster Management, Government of India. Retrieved from : Retrieved from https://ndma.gov.in/en/

Government of Uttar Pradesh. Retrieved from : Ghaziabad.nic.in

ICRISAT Report (2012), "Vulnerability to climate change : adaptation strategies and layers of resilience". Policy Brief 18.

India Water Portal : precipitation data retrieved from : Retrieved from https://www.indiawaterportal.org/

Jha, B., \& Tripathi, A. (2017), "How suspectible is India's food basket to climate change". Social Change, 47(1), pp-11-27. Retrieved from https://doi.org/10.1177/0049085716681902

M. G. Kendall, (1975) Rank Correlation Methods, Griffin, London, UK.

Mann, H.B., (1945) "Nonparametric tests against trend," Econometrica, vol. 13, pp. 245-259, Retrieved from https://doi.org/10.2307/1907187

Roy, R, \& Ahmad, H. (2015), "State agricultural profile. Agro Economic Research Centre, University of Allahabad.

Suhaila, J., Jemain, A. A., Hamdan, M. F. and Zin, W. Z. W., (2011), "Comparing rainfall patterns between regions in Peninsular Malaysia via a functional data analysis technique", J. Hydrol., 411, 3, 197-206, https:// doi.org/10.1016/j.jhydrol.2011.09.043. Retrieved from https://doi.org/10.1016/j.jhydrol.2011.09.043 
Tripathi, A. (n.d), "Doubling farmers' income by (2022) - opportunities and constraints". Report by Indian Economic Growth.

Tripathi, A., \& Mishra, A.K. (2017), "Knowledge and passive adaptation to climate change : an example from Indian farmers". Climate Risk Management, 16, pp-195-207. Retrieved from https://doi.org/10.1016/j.crm.2016.11.002

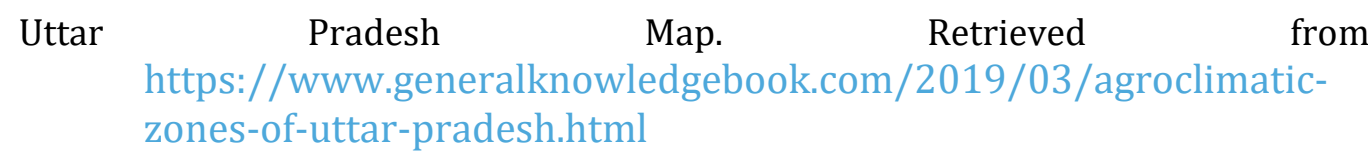

